\title{
A kinetic study of the reaction of atomic oxygen with $\mathrm{SO}_{2}$
}

\author{
Jacinth Naidoo, A. Goumri, Paul Marshall* \\ Department of Chemistry, University of North Texas, P.O. Box 305070, Denton, TX 76203-5070, USA
}

\begin{abstract}
The effective second-order rate constant for $\mathrm{O}+\mathrm{SO}_{2}(+\mathrm{Ar}) \rightarrow \mathrm{SO}_{3}(+\mathrm{Ar})$ has been measured by pulsed laser-photolysis with resonance fluorescence detection of atomic oxygen under pseudo-first-order conditions. The pressure dependence was determined at five temperatures in the range $290-840 \mathrm{~K}$. The results obtained at pressures up to $880 \mathrm{mbar}$ reveal fall-off behavior. With an estimated broadening parameter $F_{c}$, Troe fits to the measurements yield the low-pressure limit $k_{0}=9.5 \times 10^{-23} T^{-3} \exp (-2400 / T) \mathrm{cm}^{6}$ molecule $\mathrm{e}^{-2} \mathrm{~s}^{-1}$ and the high-pressure limit $k_{\infty}=6.1 \times 10^{-13} \exp (-850 / T) \mathrm{cm}^{3}$ molecule ${ }^{-1} \mathrm{~s}^{-1}$. An RRKM extrapolation of the present $k_{0}$ values yields $k_{0}=6.7 \times 10^{-21} T^{-3.6} \exp (-2610 / T) \mathrm{cm}^{6}$ molecule $\mathrm{e}^{-2} \mathrm{~s}^{-1}$, which is in good accord with several literature values over $220-2500 \mathrm{~K}$. At low temperatures, $k_{0}$ shows a positive activation energy rationalized in terms of a barrier of $15.9 \mathrm{~kJ} \mathrm{~mol}^{-1}$, and $k_{0}$ reaches a maximum at around $750 \mathrm{~K}$. Our expression for $k_{\infty}$ is in order-of-magnitude accord with values used to model a flow reactor and indicates a small pre-exponential factor. This may reflect the probability of triplet-singlet transitions in the spin-forbidden addition reaction and/or a tight transition state.
\end{abstract}

(C) 2004 The Combustion Institute. Published by Elsevier Inc. All rights reserved.

Keywords: $\mathrm{SO}_{2} ; \mathrm{SO}_{3}$; RRKM; Kinetics

\section{Introduction}

The second-order rate constant $k$ for reaction of ground-state $\mathrm{O}^{3} \mathrm{P}_{\mathrm{J}}$ atoms with $\mathrm{SO}_{2}$ is pressure-dependent, which suggests that the reaction may be written as

$\mathrm{O}+\mathrm{SO}_{2}(+\mathrm{M}) \rightarrow \mathrm{SO}_{3}(+\mathrm{M})$

Previous studies with several different bath gases $\mathrm{M}$ have yielded low-pressure limiting values $k_{0}$ in the third-order regime, where $k=k_{0}[\mathrm{M}]$, as summarized in [1] and references therein. Unlike most recombination reactions, $k_{0}$ shows a positive temperature dependence at low to moderate tem-

\footnotetext{
* Corresponding author: Fax: +1 9405654318.

E-mail address: marshall@unt.edu (P. Marshall).
}

peratures $T=220-440 \mathrm{~K}[2-4]$. Data from the reverse reaction at $T=1700-2500 \mathrm{~K}$ imply a negative temperature dependence there, and therefore that $k_{0}$ reaches a maximum at intermediate temperatures $[5,6]$. The present work describes the first experiments in this region. Also for the first time, sufficiently high pressures are reached to reveal fall-off behavior in $k$ directly, which permits an assessment of the second-order high-pressure limit, where $k=k_{\infty}$. Previously, Atkinson et al. [7] expected that transition to the high-pressure range might occur at pressures "not too far" above 1 bar. Since then, Mueller et al. [8] have argued that $k$ is in the fall-off regime at pressures above 1 bar around $1000 \mathrm{~K}$, based on flow reactor modeling. Because atomic $\mathrm{O}$ has a triplet electronic ground state while $\mathrm{SO}_{2}$ and $\mathrm{SO}_{3}$ are singlet electronic states, $k_{0}$ and $k_{\infty}$ are of theoretical 
interest because they describe a relatively rare, spin-forbidden association reaction. These rate parameters are of practical impact because they characterize a process important in combustion. Reaction (1) is the major path for formation of the significant pollutant $\mathrm{SO}_{3}$ during the combustion of coal and other sulfur-containing fuels [9], and it propagates cycles for removal of atomic oxygen catalytically by $\mathrm{SO}_{2}$. These cycles involve $\mathrm{O}+\mathrm{SO}_{3} \rightarrow \mathrm{O}_{2}+\mathrm{SO}_{2}$, especially in lean flames $[10,11]$, and/or reaction of $\mathrm{H}$ or $\mathrm{HO}_{2}$ with $\mathrm{SO}_{3}$ [8]. Such cycles are important because they provide mechanisms for sulfur to affect the overall radical pool in flames.

Here, we present new measurements of $k$ over $290-840 \mathrm{~K}$ at pressures of up to $880 \mathrm{mbar}$ $\mathrm{Ar}$ and rationalize the results in terms of RRKM theory [12]. The low-pressure limiting results are in agreement with several previous studies, and RRKM extrapolation over 220$2500 \mathrm{~K}$ is in excellent accord with measurements at those temperatures. The new high-pressure limiting information, obtained by RRKM extrapolation of the observed fall-off curves, is consistent with data needed to rationalize flow reactor studies.

\section{Methodology}

$\mathrm{SO}_{2}(99.8 \%$, MG Industries) was separated from high boiling point impurities by freezepump-thaw cycles with a liquid nitrogen/methanol slush at $175 \mathrm{~K}$. Low-boiling point impurities were removed by distillation of the $\mathrm{SO}_{2}$ from a slush at $263 \mathrm{~K}$. Mixtures of $\mathrm{SO}_{2}$ in Ar were prepared by filling a bulb with several mbar of gas evaporated from solid $\mathrm{SO}_{2}$ at $223 \mathrm{~K}$, which was made up to 1300 mbar with $\operatorname{Ar}(99.9999 \%$, Air Liquide) and allowed to mix overnight.

Atomic oxygen was generated by pulsed excimer laser-photolysis of a small fraction of $\mathrm{SO}_{2}$ at $193.3 \mathrm{~nm}$. While the absolute concentration of $\mathrm{O}$ is not required for the pseudo-first-order kinetic analysis outlined below, $[\mathrm{O}]$ may be determined from the laser pulse energy $I_{0}$, the beam area of $0.6 \mathrm{~cm}^{2}$, and the absorption cross-section $\sigma$ of $\mathrm{SO}_{2} . \sigma$ is defined by the Beer-Lambert relation

$I_{\mathrm{tr}}=I_{0} \exp \left(-\sigma\left[\mathrm{SO}_{2}\right] \ell\right)$.

We have carried out new measurements of $\sigma$ at $295 \mathrm{~K}$ in a flowing gas cell $(\ell=35 \mathrm{~cm})$ using the excimer laser (MCB PSX-100) as the source of incident radiation. Three runs with various pressures of $1 \% \mathrm{SO}_{2}$ in $\mathrm{Ar}$, with $I_{0} \approx 45 \mu \mathrm{J}$, and pulse repetition rates of $2-10 \mathrm{~Hz}$ gave consistent Beer-Lambert plots with maximum absorbances of 0.8 . The mean $\sigma$ is $(7.4 \pm 0.4) \times 10^{-18} \mathrm{~cm}^{2}$ molecule $^{-1}$, where the error limit is one standard deviation and allows for uncertainty in $\left[\mathrm{SO}_{2}\right]$. Our value lies between prior values of 6 and $8.2 \times 10^{-18} \mathrm{~cm}^{2}$ molecule ${ }^{-1}$
$[13,14]$. Fockenberg and Preses [13] report that the yield of $\mathrm{O}$ from $193 \mathrm{~nm}$ photolysis of $\mathrm{SO}_{2}$ decreases by $40 \%$ from 345 to $925 \mathrm{~K}$, while Vattulainen et al. examined UV spectra of $\mathrm{SO}_{2}$ at wavelengths down to $200 \mathrm{~nm}$ at 873 and $1073 \mathrm{~K}$ [15]. On the assumption that the temperature dependence of $\sigma$ is the same at 193 and $200 \mathrm{~nm}$, we combine this information into $\sigma=(1.16-T)$ $1900) \times 7.4 \times 10^{-18} \mathrm{~cm}^{2}$ molecule ${ }^{-1}$ for $T=300$ $1070 \mathrm{~K}$, with an uncertainty of around $15 \%$. This expression was used to estimate the initial $[\mathrm{O}]$ in the kinetic experiments with the assumption that the photolysis quantum yield is 1 and independent of $T$ and $P$.

Details of the kinetic apparatus have been given elsewhere [16-18]. Briefly, $\mathrm{SO}_{2}$ diluted in $\mathrm{Ar}$ bath gas flowed through a stainless steel reaction cell. Actinic radiation at $193 \mathrm{~nm}$ entered through one side arm and probe radiation from a resonance lamp through a second side arm. This probe radiation at $\lambda \approx 130 \mathrm{~nm}\left[\mathrm{O}(3 \mathrm{~s}){ }^{3} \mathrm{~S} \rightarrow \mathrm{O}(2 \mathrm{p}){ }^{3} \mathrm{P}_{\mathrm{J}}\right]$ was generated from a microwave discharge through a flow of $0.9 \% \mathrm{O}_{2}$ in $\mathrm{Ar}$ at a pressure of 0.4 mbar and focused through calcium fluoride optics. The relative concentration of $\mathrm{O}$ atoms was measured by time-resolved resonance fluorescence observed through a third mutually perpendicular side arm. The fluorescence passed through a calcium fluoride window and detected with a solar-blind photomultiplier tube. Signals from up to 6000 decays were averaged via an amplifier/discriminator and multi-channel scaler to improve the signal-to-noise ratio. The temperature in the reaction zone, defined by the intersection of the three side arms, was measured with a retractable, sheathed, unshielded thermocouple corrected for radiation errors [19]. Reagent gas flows were set with calibrated mass-flow controllers, and experiments were carried out with a large excess of Ar bath gas. The photolysis rate was 1$2 \mathrm{~Hz}$ to allow fresh gas mixtures to enter the reaction zone between pulses. $\mathrm{SO}_{2}$

$\mathrm{O}$ atoms are mainly consumed by reaction with

$\mathrm{d}[\mathrm{O}] / \mathrm{d} t=-\left(k\left[\mathrm{SO}_{2}\right]+k^{\prime}\right)[\mathrm{O}]=-k_{p s 1}[\mathrm{O}]$,

where $k^{\prime}$ accounts for losses other than through reaction (1), including diffusion out of the reaction zone and reaction with impurities, photolysis products (such as $\mathrm{SO}$ ) or reaction products (such as $\mathrm{SO}_{3}$ ). Under our conditions, $\left[\mathrm{SO}_{2}\right] \gg[\mathrm{O}]$, loss of $\mathrm{O}$ is pseudo-first-order with a decay coefficient $k_{p s 1}=k\left[\mathrm{SO}_{2}\right]+k^{\prime} . k_{p s 1}$ is determined from nonlinear least squares fitting of the fluorescence signals to exponential decays. A linear plot of $k_{p s 1}$ vs. $\left[\mathrm{SO}_{2}\right]$ has a slope equal to the effective second-order rate constant $k$. Figure 1 shows an example. Experiments were carried out to determine the dependence of $k$ on $T$ and [Ar] and to investigate the influence of experimental parameters such as the laser pulse energy $I_{0}$ and the aver- 


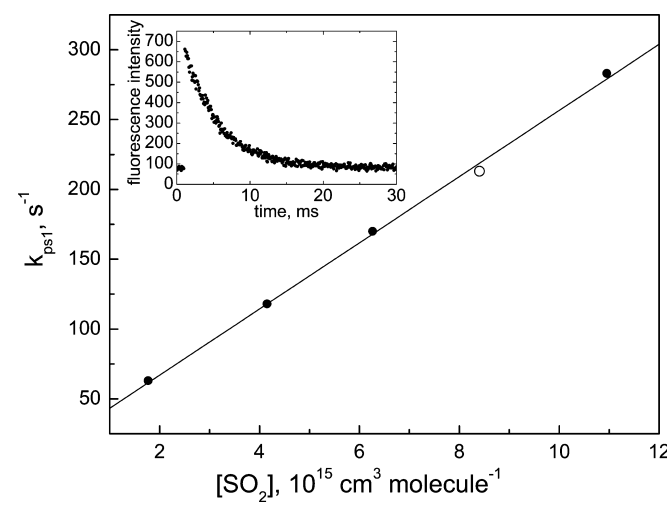

Fig. 1. Plot of pseudo-first-order decay coefficient for loss of $\mathrm{O}$ vs. $\left[\mathrm{SO}_{2}\right]$ at $T=841 \mathrm{~K}$ and $p=748 \mathrm{mbar}$. The inset shows the fluorescence decay corresponding to the open point.

age gas residence inside the heated cell before photolysis $\tau_{\text {res }}$. These, in turn, impact $[\mathrm{O}]_{0}$ and the extent of thermal decomposition of $\mathrm{SO}_{2}$.

Some special precautions were taken in these experiments. $\mathrm{SO}_{2}$ flowed through the reactor for at least an hour before experiments to passivate the surfaces with respect to adsorption. The photolysis beam was attenuated to reach a region where the measured $k$ did not vary with changes in $I_{0}$. At room temperature, where $k$ is the smallest, $I_{0}=12-34 \mu \mathrm{J}$ was employed. At higher temperatures, up to $120 \mu \mathrm{J}$ were used. Under these conditions of low $[\mathrm{O}]_{0}$, interference by secondary chemistry involving $\mathrm{SO}$ and $\mathrm{SO}_{3}$ was minimized. $\mathrm{SO}_{2}$ is itself a potential third-body $\mathrm{M}$ in reaction (1), about nine times more efficient than $\operatorname{Ar}$ [3]. Accordingly, experiments were conducted at $\mathrm{Ar}$ pressures typically above $100 \mathrm{mbar}$ to ensure that $\mathrm{M}=\mathrm{Ar}$ is the dominant collisional stabilization partner. Diffusional loss of O dominates the intercept of plots such as Fig. 1 and is separated from reactive loss of $\mathrm{O}$ by variation of $\left[\mathrm{SO}_{2}\right]$. At lower pressures, a difficulty is that diffusional contributions to $k_{p s 1}$ via $k^{\prime}$ become large (as indicated in tabulated measurements in the electronic supplementary material) while the $[\mathrm{M}]$-dependent $k$ drops, so that the overall variation in $k_{p s 1}$ with $\left[\mathrm{SO}_{2}\right]$ becomes small. The abstraction process $\mathrm{O}+\mathrm{SO}_{2} \rightarrow \mathrm{O}_{2}+\mathrm{SO}_{2}$ is negligibly slow under our conditions, with a rate constant below $10^{-16} \mathrm{~cm}^{3}$ molecule ${ }^{-1}[1]$.

\section{Results}

Tables summarizing 53 individual $k$ measurements and their conditions are provided in the electronic supplementary material. Data were obtained at 5 temperatures over $290-840 \mathrm{~K}$. Each $k$ value is based on at least 5 values of $k_{p s 1}$. Typical minimum $\left[\mathrm{SO}_{2}\right]$ values were of the order of $(0.02-$
$0.1) \times 10^{16}$ molecule $\mathrm{cm}^{-3}$, and typical maximum $\left[\mathrm{SO}_{2}\right]$ values were of the order of $(0.5-$ $5) \times 10^{16}$ molecule $\mathrm{cm}^{-3}$. $[\mathrm{O}]_{0}$ is proportional to $\left[\mathrm{SO}_{2}\right]$ and varied over $(0.2-70) \times 10^{12}$ molecule $\mathrm{cm}^{-3}$. The $k$ results are shown in Fig. 2 as a function of [Ar]. Within the scatter of the data at each temperature, the results do not vary significantly with $I_{0}$ or $\tau_{\text {res }}$. This indicates that mixing was attained, that thermal decomposition was negligible, and that reaction (1) was isolated from secondary chemistry. The error bars shown in Fig. 2 represent the statistical uncertainty in the plot of $k_{p s 1}$ vs. $\left[\mathrm{SO}_{2}\right]$ (one standard deviation) and do not include systematic errors.

Figure 2 indicates that results were obtained in the fall-off region. The $k$ data are rationalized in terms of unimolecular RRKM rate theory by application of the approximate master equation solutions of Troe [12] for the general scheme

$$
\begin{aligned}
& \mathrm{O}+\mathrm{SO}_{2} \leftrightarrow \mathrm{SO}_{3}^{*} \\
& \mathrm{SO}_{3}^{*}+\mathrm{M} \rightarrow \mathrm{SO}_{3}+\mathrm{M}
\end{aligned}
$$

Within this framework, the pressure-dependent $k$ at a given $T$ can be expressed as

$$
\begin{aligned}
& k=\left(\frac{k_{0}[\mathrm{M}]}{1+k_{0}[\mathrm{M}] / k_{\infty}}\right) \\
& \times F_{c}^{\left\{1+\left[\log _{10}\left(k_{0}[\mathrm{M}] / k_{\infty}\right) /\left(0.75-1.27 \log _{10} F_{c}\right)\right]^{2}\right\}^{-1}} \text {. }
\end{aligned}
$$

The broadening parameter $F_{c}$ was estimated as outlined by Troe [20] and then the parameters $k_{0}$ and $k_{\infty}$ were varied to obtain the best fit with our measurements.

Several mechanisms have been proposed for reaction (1), which differ as to the location of intersystem crossing and potential barriers [2,5,21]. Here, we implement the assumptions of Astholtz et al. [5] that a barrier arises at the intersection of a repulsive triplet $\mathrm{O}+\mathrm{SO}_{2}$ surface with a singlet $\mathrm{SO}_{3}$ Morse potential, and that the $\mathrm{SO}_{3}^{*}$ intermediate is an energized singlet $\mathrm{SO}_{3}$ molecule. Astholtz et al. [5] estimated that the critical geometry for the formation of $\mathrm{SO}_{3}^{*}$ occurs at $r(\mathrm{~S}-\mathrm{O})=2.05 \AA$ for the newly forming bond, with the structure of $\mathrm{SO}_{2}$ unchanged. We use this value here together with the vibrational frequencies of $\mathrm{SO}_{3}$ [22], an exponential correlation of $v$ and $r$ [23], and a standard loosening parameter $\alpha=1 \AA^{-1}$ [12], to estimate frequencies in the transition state of $266,285,524,1106$, and $1378 \mathrm{~cm}^{-1}$. These values are used to evaluate the vibrational partition function $Q^{\ddagger}$. The enthalpy at $0 \mathrm{~K}$ of $\mathrm{SO}_{3}^{*}$ above $\mathrm{O}+\mathrm{SO}_{2}$ is $V_{0}$, previously estimated to be $13.8 \pm 4 \mathrm{~kJ} \mathrm{~mol}^{-1}$ [5]. The enthalpy above $\mathrm{SO}_{3}$ is $E_{0}=V_{0}+\Delta H_{0}$, where $\Delta H_{0}$ is the bond dissociation enthalpy of $\mathrm{SO}_{3}, 342.5 \pm 0.7 \mathrm{~kJ} \mathrm{~mol}^{-1}$ [22].

We apply the standard Troe formalism [12] with a similar notation in this work, and unless noted use the same input data as Astholtz et al. [5]. The variation of $Q^{\ddagger}$ with temperature yields 

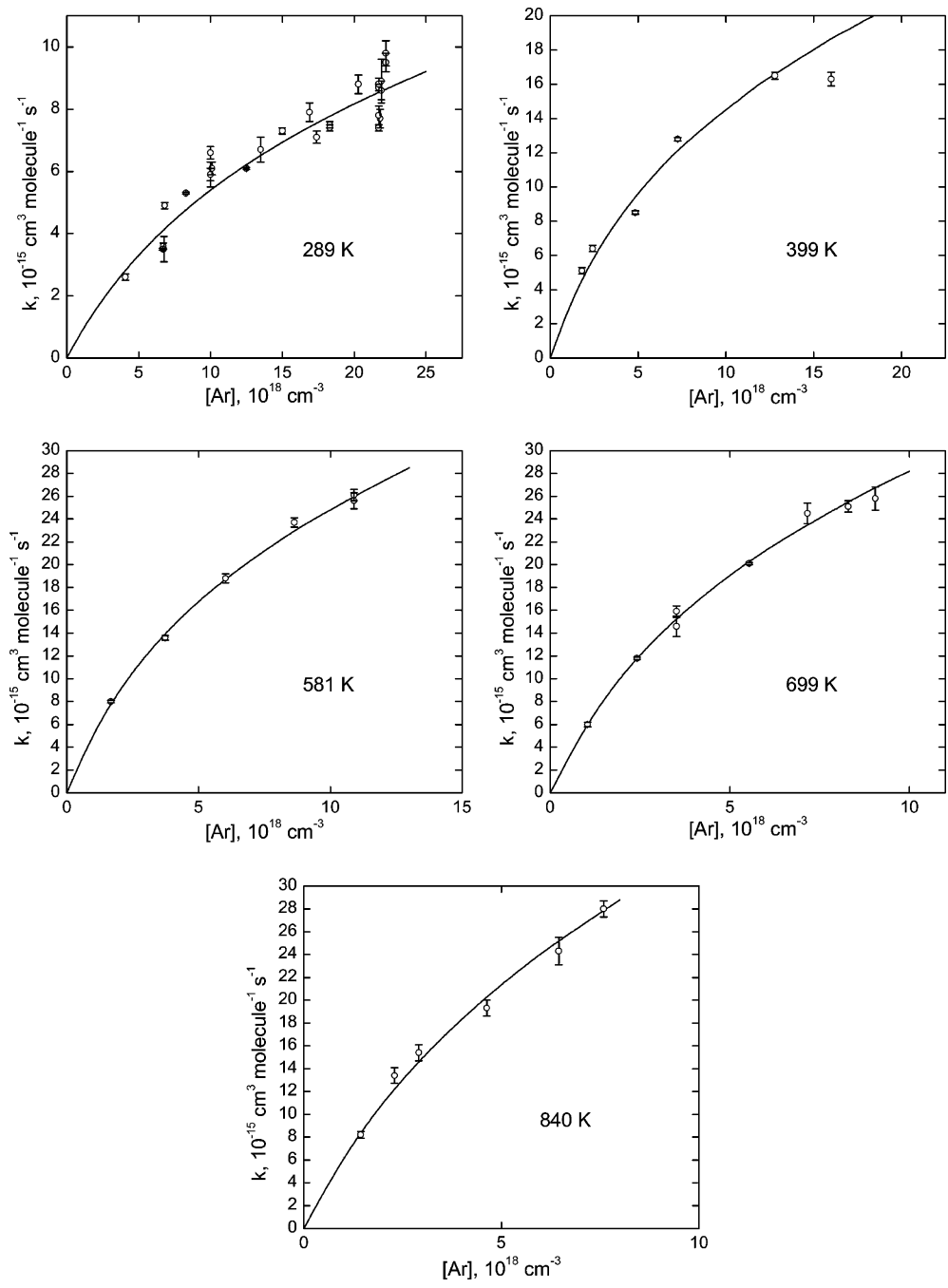

Fig. 2. Measurements of the effective second-order rate constant for $\mathrm{O}+\mathrm{SO}_{2}(+\mathrm{Ar}) \rightarrow \mathrm{SO}_{3}(+\mathrm{Ar})$ at 289, 399, 581, 699, and $840 \mathrm{~K}$ as function of [Ar]. The solid curves are fits to a fall-off expression (see text).

the $S_{\mathrm{K}}$ parameter, an effective number of oscillators, via the relation $S_{\mathrm{K}}=1-\frac{1}{T} \frac{\mathrm{d} \ln Q^{\ddagger}}{\mathrm{d} 1 / T}[20]$, from which $F_{c}$ is derived (see Table 1). $F_{c}$ incorporates strong and weak collision broadening effects. Figure 2 shows the fits obtained, and each $k$ value was weighted inversely to the square of its statistical uncertainty. The resulting $k_{0}$ and $k_{\infty}$ values are given in Table 1 and plotted in Figs. 3 and 4. They may be summarized as:

$$
\begin{aligned}
k_{0}= & 9.5 \times 10^{-23} \mathrm{~T}^{-3} \\
& \times \exp (-2400 / T) \mathrm{cm}^{6} \text { molecule }^{-2} \mathrm{~s}^{-1}, \\
k_{\infty}= & 6.1 \times 10^{-13} \\
& \times \exp (-850 / T) \mathrm{cm}^{3} \text { molecule } \mathrm{s}^{-1} .
\end{aligned}
$$

\section{Discussion}

\subsection{Low-pressure limit}

It may be seen that $k_{0}$ levels off at around $750 \mathrm{~K}$, which is the region where a maximum was predicted by Astholtz et al. [5]. This behavior reflects two competing factors: as the temperature is raised, surmounting the energy barrier $V_{0}$ becomes easier, but eventually the efficiency of collisional stabilization of $\mathrm{SO}_{3}^{*}$ decreases more rapidly. There are differing measurements of the relative efficiency of different bath gases. For example, Timmons et al. [24] reported that $k_{0}(\mathrm{Ar}) / k_{0}(\mathrm{He})=1.25$, whereas Davis found 1.93 for the same ratio [2], so here we compare our $k_{0}$ only with prior work where Ar was directly 
Table 1

Fall-off parameters for the reaction $\mathrm{O}+\mathrm{SO}_{2}(+\mathrm{Ar}) \rightarrow \mathrm{SO}_{3}(+\mathrm{Ar})$

\begin{tabular}{llll}
\hline$T(\mathrm{~K})$ & $F_{c}$ & $k_{0}\left(10^{-33} \mathrm{~cm}^{6} \mathrm{molecule}^{-2} \mathrm{~s}^{-1}\right)$ & $k_{\infty}\left(10^{-13} \mathrm{~cm}^{3} \mathrm{molecule}^{-1} \mathrm{~s}^{-1}\right)$ \\
\hline 289 & 0.65 & 1.0 & 0.33 \\
399 & 0.58 & 3.7 & 0.70 \\
581 & 0.50 & 7.6 & 1.3 \\
699 & 0.47 & 9.1 & 1.6 \\
840 & 0.44 & 9.1 & 2.6 \\
\hline
\end{tabular}

employed. Figure 5 summarizes several studies made close to the low-pressure limit. It may be seen that at room temperature there is good accord with the flash-photolysis resonance fluorescence study of Davis [2] and the flash-photolysis $\mathrm{O} / \mathrm{NO}$ chemiluminescence experiments of Atkinson and Pitts [3]. The earlier determinations of Halstead and Thrush [25], and Mulcahy et al. [26] appear somewhat high. We obtain a slightly steeper temperature dependence than Atkinson and Pitts, but the greatest difference between our $k_{0}$ values is only a factor of 1.5 . Given the challenges of measuring such a slow, pressure-dependent process, we consider this to be good accord. Propagation of potential systematic errors and consideration of the scatter in the plots of Fig. 2 suggest likely error limits for $k$ values, fitted via Eq. (5), of about $\pm 15 \%$.

Similar to Astholtz et al. [5], we have computed $k_{0}$ via RRKM theory by application of the relation

$$
\begin{aligned}
k_{0}= & \beta_{c} Z_{\mathrm{LJ}} F_{E} F_{\mathrm{anh}} F_{\mathrm{rot}} \frac{\rho_{\mathrm{vib}}\left(E_{0}\right) R T}{Q_{\mathrm{vib}}\left(\mathrm{SO}_{3}\right)} \\
& \times \frac{Q\left(\mathrm{SO}_{3}\right)}{Q(\mathrm{O}) Q\left(\mathrm{SO}_{2}\right)} \exp \left(\frac{-V_{0}}{R T}\right) .
\end{aligned}
$$

We used the same input parameters as they did. The barrier $V_{0}$ was adjusted to $15.9 \mathrm{~kJ} \mathrm{~mol}^{-1}$ to match our $k_{0}(298 \mathrm{~K})$, with the same $-\langle\Delta E\rangle$ of

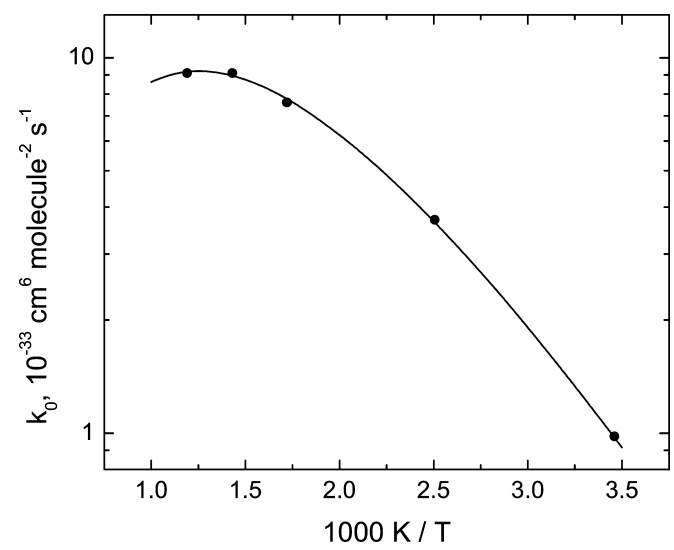

Fig. 3. Arrhenius plot of the interpolated low-pressure limit $k_{0}$ for $\mathrm{O}+\mathrm{SO}_{2}(+\mathrm{Ar}) \rightarrow \mathrm{SO}_{3}(+\mathrm{Ar})$. The curve is a fit to the modified Arrhenius expression $A T^{n} \exp (-B / T)$ (see text).

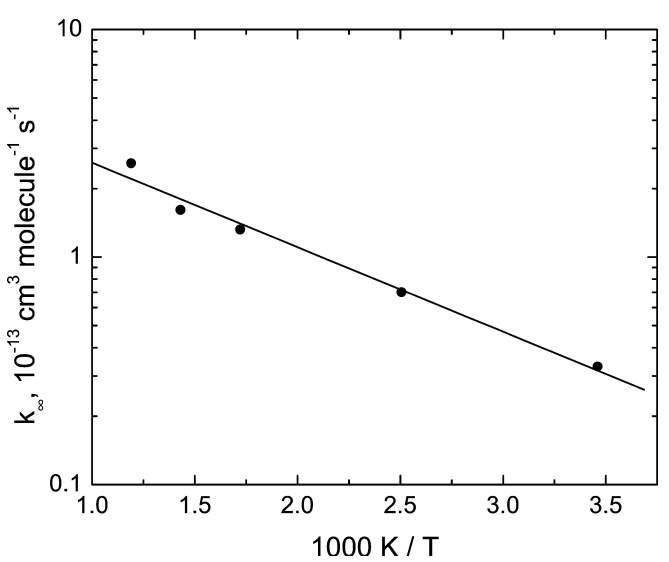

Fig. 4. Arrhenius plot of the extrapolated high-pressure limit $k_{\infty}$ for $\mathrm{O}+\mathrm{SO}_{2}(+\mathrm{Ar}) \rightarrow \mathrm{SO}_{3}(+\mathrm{Ar})$.

$3000 \mathrm{~J}$ at $298 \mathrm{~K}$. We allowed for temperature variation of the energy transferred upon collisional stabilization via the relation $-\langle\Delta E\rangle \propto T^{n}$, and determined $n=-0.42$ by matching the calculated $k_{0}$ with our measurements at $800 \mathrm{~K}$. Over 220 $2500 \mathrm{~K}$ our computed $F_{c}$ can be summarized as $0.558 \exp (-T / 316)+0.442 \exp (-T / 7442)$. The full RRKM calculation over $220-2500 \mathrm{~K}$ is shown in Fig. 5. This calculation, which rationalizes our measurements, is seen to extrapolate very well over a wide range of temperatures and may be represented to within ca. $15 \%$ as $k_{0}=6.7 \times 10^{-21}$ $T^{-3.6} \exp (-2610 / T) \mathrm{cm}^{6}$ molecule $\mathrm{s}^{-1}$. The agreement with several sets of measurements does not prove that the underlying mechanistic assumptions are correct, but the RRKM treatment does provide a physically based model to summarize the results. Together with our expression for $k_{\infty}$ (Eq. (7)), it enables $k$ to be predicted over a wide range of conditions.

\subsection{High-pressure limit}

There are no prior measurements of $k_{\infty}$ for comparison. Kinetic studies of quenching of vibrationally excited $\mathrm{SO}_{2}$ by atomic oxygen and isotopic exchange between $\mathrm{O}$ and $\mathrm{SO}_{2}$ yield rate constants of $(1-2) \times 10^{-12} \mathrm{~cm}^{3}$ molecule $\mathrm{s}^{-1} \mathrm{~s}^{-1}[27,28]$. In general such experiments can give information about the high-pressure limit for recombination, 


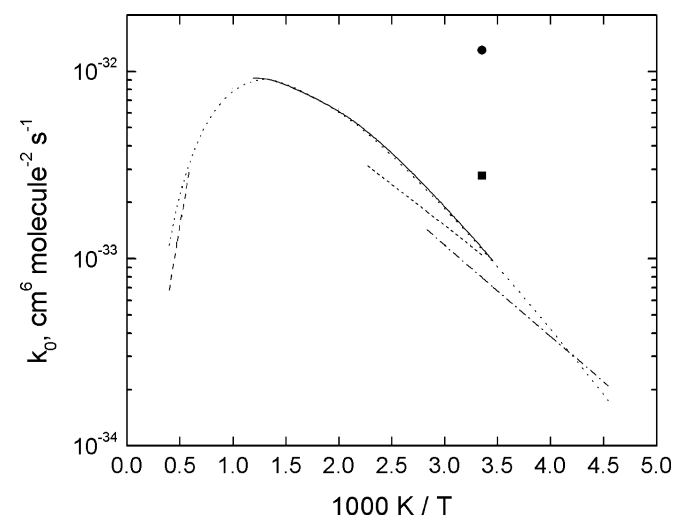

Fig. 5. Plot of measured low-pressure limits $k_{0}$ for $\mathrm{O}+\mathrm{SO}_{2}(+\mathrm{Ar}) \rightarrow \mathrm{SO}_{3}$ (+Ar). Solid line, this work; dashes, Astholtz et al. [5]; short dashes, Atkinson and Pitts [3]; dash-dot, Davis [2]; square, Mulcahy et al. [26]; and circle, Halstead and Thrush [25]. The dotted curve is an RRKM calculation (see text).

but in the case of the $\mathrm{O}+\mathrm{SO}_{2}$ interaction Astholtz et al. [5] note that they may proceed in a spin-allowed manner entirely on a triplet surface, without intersystem crossing to a single state.

Mueller et al. [8] have developed an expression for $k_{\infty}$ in part by analogy with that for the spin-forbidden $\mathrm{O}+\mathrm{CO}$ recombination, and in part by matching observed concentration profiles when moist $\mathrm{CO}$ was oxidized in the presence of traces of $\mathrm{NO}$ and $\mathrm{SO}_{2}$ at around $1000 \mathrm{~K}$. They assumed $F_{c}=1$, i.e., the Lindemann model, so our RRKM model should be more realistic. Their proposed $k_{\infty}(1000 \mathrm{~K})$ is a factor of 5.7 smaller than that from Eq. (7). This is reasonable agreement, considering that our own $k_{\infty}$ values reflect considerable pressure extrapolation, that Mueller et al. suggest a factor of 2 uncertainty in their $k_{\infty}$, and that a factor 5.7 increase in $k_{\infty}$ would have only a modest impact on their $\mathrm{CO}$ and $\mathrm{SO}_{2}$ profiles.

$k_{\infty}$ is of the order of $10^{-13} \mathrm{~cm}^{3}$ molecule $\mathrm{e}^{-1} \mathrm{~s}^{-1}$, some two orders of magnitude below typical values for spin-allowed reactions [6]. As Astholtz et al. point out, within the context of their mechanism, $k_{\infty}$ incorporates the probability of intersystem crossing (unlike $k_{0}$, where at the low-pressure limit equilibrium is maintained between reactants and singlet $\mathrm{SO}_{3}[5]$ ). Presumably probabilities below 1 account in part for the small pre-exponential factor. The transition state may also be unusually tight. This aspect is being investigated in our laboratory via ab initio methods. A potential difficulty with the Astholtz et al. mechanism is that the derived activation energy $E_{\mathrm{a}}$ for $k_{\infty}$ of $7 \mathrm{~kJ} \mathrm{~mol}^{-1}$ is smaller than the barrier $V_{0}$. We may speculate that the intersystem crossing probability decreases with temperature, which would tend to lower $E_{\mathrm{a}}$.

\section{Conclusions}

Direct measurements of the effective secondorder rate constant for $\mathrm{O}+\mathrm{SO}_{2}(+\mathrm{Ar}) \rightarrow \mathrm{SO}_{3}$ $(+\mathrm{Ar})$ over $290-840 \mathrm{~K}$ reveal pressure fall-off behavior. Troe fits yield low- and high-pressure limiting rate constants. The former exhibit a maximum near $750 \mathrm{~K}$, and are rationalized in terms of an energy barrier to the spin-forbidden addition. The high-pressure limit exhibits a modest positive temperature dependence and has a small pre-exponential factor, suggesting that triplet-singlet crossing has a low probability and/or that the reaction passes through a tight transition state. The high-pressure limit is compatible with a recent flow reactor model.

\section{Acknowledgments}

This work was supported by the National Science Foundation (Grant CTS-0113606), the Robert A. Welch Foundation (Grant B-1174), and the UNT Faculty Research Fund.

\section{References}

[1] D.L. Singleton, R.J. Cvetanovic, J. Phys. Chem. Ref. Data 17 (1988) 1377-1437.

[2] D.D. Davis, Can. J. Chem. 52 (1974) 1405-1414.

[3] R. Atkinson, J.N. Pitts Jr., Int. J. Chem. Kinet. 10 (1978) 1081-1090.

[4] R. Atkinson, J.N. Pitts Jr., Chem. Phys. Lett. 29 (1974) 28-30.

[5] D.C. Astholz, K. Glanzer, J. Troe, J. Chem. Phys. 70 (1979) 2409-2413.

[6] J. Troe, Annu. Rev. Phys. Chem. 29 (1978) 223-250.

[7] R. Atkinson, D.L. Baulch, R.A. Cox, R.F. Hampson Jr., J.A. Kerr, M.J. Rossi, J. Troe, J. Phys. Chem. Ref. Data 26 (1997) 521-1011 (see also $<$ http://www.iupac-kinetic.ch.cam.ac.uk $>$ ).

[8] M.A. Mueller, R.A. Yetter, F.L. Dryer, Int. J. Chem. Kinet. 32 (2000) 317-339.

[9] C.F. Cullis, M.F.R. Mulcahy, Combust. Flame 18 (1972) 225-292.

[10] C.P. Fenimore, G.W. Jones, J. Phys. Chem. 69 (1965) 3593-3597.

[11] M.A. Alzueta, R. Bilbao, P. Glarborg, Combust. Flame 127 (2001) 2234-2251.

[12] J. Troe, J. Phys. Chem. 83 (1979) 114-126.

[13] C. Fockenberg, J.M. Preses, J. Phys. Chem. A 106 (2002) 2924-2930.

[14] V. Prahlad, K. Vijay, J. Quant. Spectrosc. Rad. Transfer 57 (1997) 719-723.

[15] J. Vattulainen, L. Wallenius, J. Stenberg, R. Hernberg, V. Linna, Appl. Spectrosc. 51 (1997) 1311-1315.

[16] Y. Shi, P. Marshall, J. Phys. Chem. 95 (1991) 1654-1658.

[17] L. Ding, P. Marshall, J. Phys. Chem. 96 (1992) 2197-2201.

[18] L. Ding, P. Marshall, J. Chem. Phys. 98 (1993) 8545-8550.

[19] L. Ding, P. Marshall, J. Chem. Soc. Faraday Trans. 89 (1993) 419-423. 
[20] J. Troe, Ber. Bunsenges. Phys. Chem. 87 (1983) 161-169.

[21] A.A. Westenberg, N. de Haas, J. Chem. Phys. 63 (1975) 5411-5415.

[22] M.W. Chase Jr. (Ed.), NIST-JANAF Thermochemical Tables, fourth ed., American Chemical Society and the American Institute of Physics, Woodbury, NY, 1998.

[23] K.A. Holbrook, M.J. Pilling, S.H. Robertson, Unimolecular Reactions, second ed., Wiley, Chichester, 1996.
[24] R.B. Timmons, H.F.L. Fevre, G.A. Hollinden, Chemical Reactions in Urban Atmospheres, Elsevier, Amsterdam, 1971, p. 159.

[25] C.J. Halstead, B.A. Thrush, Proc. R. Soc. London A 295 (1966) 363-379.

[26] M.F.R. Mulcahy, J.R. Steven, J.C. Ward, D.J. Williams, Proc. Combust. Inst. 12 (1968) 54-55.

[27] G.A. West, R.E. Weston, G.W. Flynn, J. Chem. Phys. 67 (1977) 4873-4879.

[28] S. Jaffe, F.S. Klein, Trans. Faraday Soc. 62 (1966) 2150-2157. 